\title{
ANÁLISE DE FASES DE AMOSTRAS DE ESCÓRIAS SIDERÚRGICAS DO SISTEMA CaO-MgO- $\mathrm{Al}_{2} \mathrm{O}_{3}-\mathrm{SiO}_{2}{ }^{*}$
}

\author{
Leticia Gabriela Winck ${ }^{1}$ \\ Wagner Viana Bielefeldt ${ }^{2}$ \\ Antônio Cezar Faria Vilela ${ }^{3}$
}

\section{Resumo}

As escórias de aciaria, além de ser um coproduto da fabricação do aço, desempenham um papel importante na qualidade dos aços produzidos. Entender como elas se comportam durante o processo de refino é fundamental. Por exemplo, no refino secundário, a absorção de inclusões pela escória é umas das principais formas de se obter aços com maior limpeza inclusionária, e consequentemente, mais nobres. $O$ presente trabalho tem como objetivo a caracterização de fases de escórias de refino secundário do sistema CMAS ( $\left.\mathrm{CaO}, \mathrm{MgO}, \mathrm{Al}_{2} \mathrm{O}_{3}, \mathrm{SiO}_{2}\right)$, a fim de se obter informações a respeito de sua composição e fração líquida, além de prováveis fases sólidas. Para isso, quatro amostras de diferentes composições químicas foram fundidas em forno elétrico resistivo a altas temperaturas. As amostras também foram analisadas por diferentes técnicas como: microscopia eletrônica de varredura com sistema EDS acoplado (MEV/EDS), difração de raios X e simulação termodinâmica. Os resultados obtidos experimentalmente foram condizentes com as simulações termodinâmicas e com os resultados encontrados na literatura.

Palavras-chave: Caracterização; Fases; Escória; Sistema CMAS.

\section{PHASE ANALISYS OF SIDERURGIC SLAG SAMPLES FROM CaO-MgO-Al $\mathrm{O}_{3}-\mathrm{SiO}_{2}$ SYSTEM}

\section{Abstract}

Steel slag, besides being coproducts of the steelmaking process is the slag, play an important role in the quality of steel produced. Understanding how it behaves in the process of refining is fundamental. For example, in secondary refining, the inclusions' absorption by slag is one of the main ways of the obtaining cleaner products, therefore, noblest. The present study aims the phases' characterization of the refining slag from the CMAS $\left(\mathrm{CaO}, \mathrm{MgO}, \mathrm{Al}_{2} \mathrm{O}_{3}, \mathrm{SiO}_{2}\right)$ system, in order to obtain information about its compositions and liquid fraction, including probable solid phases. In order to carry it out, four samples with different chemical compositions were melted in laboratory resistive furnace, and after analyzed by different techniques: scanning electron microscope with energy dispersive spectroscopy (SEM/EDS), $x$ - ray diffraction and thermodynamic simulation. The results were consistent with the thermodynamic simulation and results in the bibliography.

Keywords: Characterization; Phases; Slags; CMAS system.

Graduanda em Engenharia Metalúrgica; Laboratório de Siderurgia (LaSid); UFRGS, Porto Alegre, RS, Brasil.

Prof., Dr.; LaSid; Depto. de Metalurgia, PPGE3M, UFRGS, Porto Alegre, RS, Brasil.

Prof.,Dr.-Ing.; LaSid; Depto. de Metalurgia, PPGE3M, UFRGS, Porto Alegre, RS, Brasil. 


\section{INTRODUÇÃO}

A busca pelo aprimoramento das técnicas de fabricação dos aços a fim de se obter produtos mais nobres, aços com maior limpidez inclusionária, tem se tornado cada vez mais importante para a indústria siderúrgica. $O$ que torna a remoção das inclusões não metálicas presentes nos aços um desafio aos profissionais metalurgistas. Inclusões são fases não metálicas que estão dispersas em uma matriz metálica e sua presença representa alterações críticas nas propriedades dos aços, prejudicando a sua aplicabilidade final [1].

Segundo a American Society for Testing and Materials (ASTM), escória é um produto não metálico, que consiste em silicatos de cálcio e ferro, combinados com óxidos de ferro, alumínio, cálcio e magnésio fundidos, que aparece como co-produto do aço resultante das atividades realizadas nas usinas integradas de aço ou nas usinas com forno elétrico a arco [2].

No contexto de limpeza inclusionária, o estudo de escórias tem se mostrado bastante promissor [3]. Entretanto, o comportamento da escória quanto à absorção de inclusões ainda não é bem esclarecido na literatura. Por isso, estudos sobre a escória com diferentes composições químicas tem se tornado de fundamental importância.

Em muitas indústrias, usa-se uma escória baseada no sistema quaternário $\mathrm{CaO}$ $\mathrm{MgO}-\mathrm{Al}_{2} \mathrm{O}_{3}-\mathrm{SiO}_{2}$. Esse sistema é adotado com frequência devido à sua alta compatibilidade com os refratários utilizados no refino secundário do aço na panela $[4,5]$.

Geralmente, a composição das escórias do sistema CMAS (CaO-MgO- $\mathrm{Al}_{2} \mathrm{O}_{3}-\mathrm{SiO}_{2}$ ) fica numa região líquida do diagrama de fase, mas esses diagramas encontrados na literatura apresentam muitas regiões incertas, que podem ser uma região de fase líquida ou múltiplas fases [4]. O que ocasiona divergências entre os resultados encontrados experimentalmente em comparação com a literatura.

Tendo em vista este contexto, este trabalho se propõe a estudar as fases presentes em algumas composições de escórias do sistema CMAS, já que entender o comportamento dessas escórias é de fundamental importância para a obtenção de mais informações sobre o assunto, o que beneficiará tanto a indústria siderúrgica quanto a literatura.

\section{MATERIAIS E MÉTODOS}

Para a caracterização das fases de escória, foram utilizadas quatro amostras produzidas no Laboratório de Siderurgia da UFRGS. A composição química das amostras possui alumina fixa igual a $20 \%$ em massa, basicidade binária constante igual a 2,0 e porcentagem de MgO variando entre 5 e 20\%. A tabela 1 apresenta a composição de cada amostra.

Tabela 1: Porcentagem em massa dos reagentes em cada amostra.

\begin{tabular}{ccccc}
\hline Amostra & $\% \mathbf{C a O}$ & $\% \mathbf{M g O}$ & $\% \mathbf{A l}_{\mathbf{2}} \mathbf{O}_{\mathbf{3}}$ & $\% \mathbf{S i O}_{\mathbf{2}}$ \\
\hline 1 & 50,00 & 5,00 & 20,00 & 25,00 \\
\hline 2 & 48,67 & 7,00 & 20,00 & 24,33 \\
\hline 3 & 43,33 & 15,00 & 20,00 & 21,67 \\
\hline 4 & 40,00 & 20,00 & 20,00 & 20,00 \\
\hline
\end{tabular}


As amostras foram pesadas, homogeneizadas e então fundidas no Forno Elétrico Resistivo a Alta Temperatura, mais informações podem ser obtidas no trabalho de Bielefeldt [6]. O forno foi programado para operar da seguinte maneira: a partir de $25^{\circ} \mathrm{C}$, a temperatura aumentou a uma taxa de $5^{\circ} \mathrm{C}$ por minuto, por um tempo de 5 horas e 15 minutos, até atingir um patamar de $1600^{\circ} \mathrm{C}$, a qual ficou constante durante duas horas. Esse tempo foi suficiente para a fusão das amostras. $O$ resfriamento das amostras foi lento, com uma taxa entre $13^{\circ} \mathrm{C} / \mathrm{min}$ a $1600^{\circ} \mathrm{C}$ e $6,5^{\circ} \mathrm{C} / \mathrm{min}$ a $1000^{\circ} \mathrm{C}$, o que evidencia uma não linearidade no resfriamento. Entretanto, espera-se que a velocidade de resfriamento seja tal que seja possível observar nas amostras solidificadas a matriz líquida (fase amorfa) e as fases sólidas formadas na temperatura de $1600^{\circ} \mathrm{C}$.

Os cadinhos utilizados na fusão das amostras são feitos de grafita de alta pureza, tendo em vista que esse material não reage quimicamente com os reagentes que compõem a escória.

Após a fusão, as amostras foram lixadas e polidas. O equipamento utilizado para ambas as etapas foi a Politriz Arotec, modelo Aropol-E. Para lixar foram utilizadas seis lixas, na seguinte ordem de granulometria: 100, 220, 400, 600, 1000 e 1200 utilizando água como lubrificante. Depois as amostras foram polidas utilizando pasta de diamante de $3 \mu \mathrm{m}$ e $6 \mu \mathrm{m}$ e álcool como lubrificante.

Como as amostras são pouco condutoras, para serem analisadas via Microscópio Eletrônico de Varredura (MEV), foi feita uma deposição de filme de carbono, material que melhora a condutividade de elétrons e torna a análise mais eficaz visualmente.

A análise química das amostras foi feita no Microscópio Eletrônico de Varredura HITACHI-TM3030 com sistema de espectrometria de raios $X$ por dispersão de energia (EDS) acoplada, localizada no Laboratório de Design e Seleção de Materiais da UFRGS. A análise foi feita com elétrons retroespalhados e a voltagem de aceleração dos mesmos foi de $15 \mathrm{kV}$. A composição química elementar foi convertida para a forma dos óxidos mais estáveis e normalizada.

Para a difração de raios $X$ as amostras foram moídas no Moinho de Recipiente Vibratório Astecma, localizado no Laboratório de Processamento Mineral da UFRGS e posteriormente peneiradas até uma granulometria inferior a 325 mesh, ou 0,044 $\mathrm{mm}$. A difração foi realizada utilizando o aparelho Philips X'Pert, com varredura de 5 a 75 graus, do Laboratório de Materiais Cerâmicos da UFRGS. Como ferramenta para a caracterização das fases, foi utilizado o programa Philips X'Pert Graphics and identify.

Já a simulação termodinâmica foi feita no programa comercial FactSage, versão 6.4, com os bancos de dados FToxid e FactPS. Descrição sobre o software e seus bancos de dados são obtidos em Bale et al [7], com algumas modificações [8].

\section{RESULTADOS E DISCUSSÃO}

\subsection{Resultados Obtidos via Simulação Termodinâmica}

Inicialmente, foram plotados os diagramas pseudoternários a partir das composições químicas de cada amostra, explícitas na tabela 1. O diagrama foi calculado mantendo-se a alumina fixa, na temperatura de $1600^{\circ} \mathrm{C}$, já que esta foi o patamar de fusão das amostras. Depois, foi traçada a linha de isobasicidade.

A figura 1 mostra o diagrama obtido e os diferentes pontos de composição de MgO. 


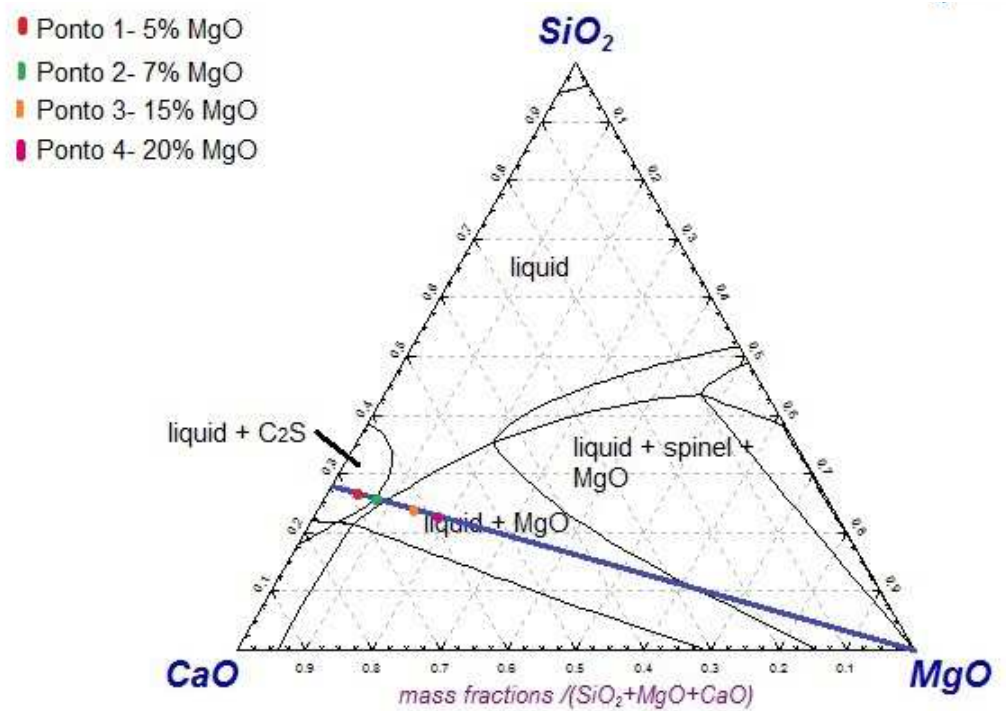

Figura 1: Corte isotérmico no diagrama pseudoternário do sistema CMAS a $1600^{\circ} \mathrm{C}$.

O que se observa no diagrama é que apenas o ponto 2, que corresponde a amostra 2 (7\% de $\mathrm{MgO}$ ) se encontra na área totalmente líquida do diagrama, então, esperase que escórias com a composição química da amostra 2 sejam totalmente líquidas a $1600^{\circ} \mathrm{C}$.

O ponto 1 , correspondente a amostra 1 ( $5 \%$ de $\mathrm{MgO}$ ) se encontra numa região do diagrama onde espera-se que exista fase líquida e fase sólida de $2 \mathrm{CaO} . \mathrm{SiO}_{2}$. Já os pontos 3 e 4,15 e $20 \%$ de $\mathrm{MgO}$, respectivamente, se encontram numa região do diagrama onde estima-se encontrar fase líquida e fase sólida de $\mathrm{MgO}$.

Pela análise da figura 1, observa-se que apenas as amostras 3 e 4 serão saturadas em $\mathrm{MgO}$. A saturação é importante, pois o $\mathrm{MgO}$ atua para tornar a escória compatível com os diversos refratários utilizados no refino do aço [9].

As fases esperadas em cada amostra estão apresentadas na tabela 2. Considera-se que as fases sólidas são soluções que podem conter outros óxidos em sua composição.

Tabela 2 - Fases esperadas em cada amostra.

\begin{tabular}{cc}
\hline Amostra & Fases Esperadas \\
\hline 1 & Fase líquida + fase sólida de $2 \mathrm{CaO} \mathrm{SiO}_{2}$ \\
\hline 2 & Fase líquida \\
\hline 3 & Fase líquida + fase sólida de $\mathrm{MgO}$ \\
\hline 4 & Fase líquida + fase sólida de $\mathrm{MgO}$ \\
\hline
\end{tabular}

\subsection{Resultados Obtidos Experimentalmente}

Os resultados estão divididos em dois tópicos: Análise de MEV/EDS e Difração de raios X. No primeiro tópico serão apresentadas as micrografias das amostras, seguidas da composição química dos pontos analisados. Além disso, serão mostradas as composições de fases sólidas e líquidas obtidas via simulação termodinâmica. Já no segundo tópico serão apresentados os resultados da difração de raios $X$. 


\subsubsection{Análise de MEV/EDS}

Após a etapa de fusão e preparação das amostras, estas foram analisadas no microscópio eletrônico de varredura (MEV/EDS).

\section{Amostra 1}

A figura 2 representa a micrografia da amostra de escória que contém $5 \%$ de $\mathrm{MgO}$.

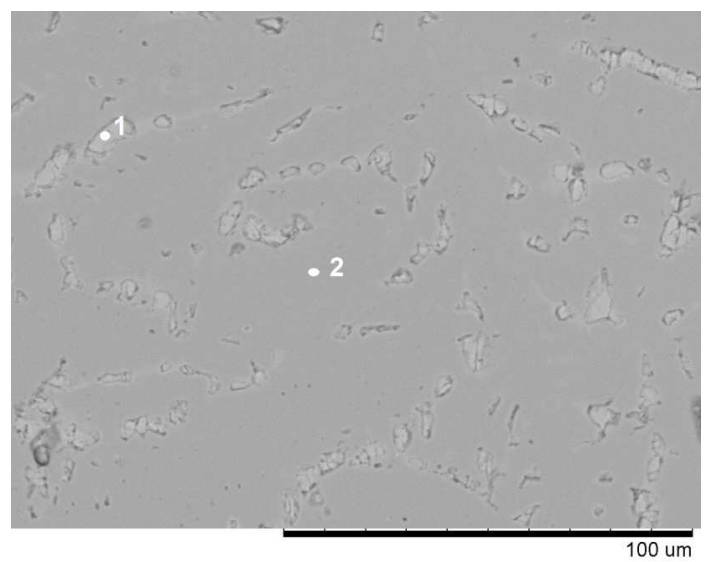

Figura 2: Pontos 1 e 2 analisados na amostra de 5\% de MgO. Aumento de 2000x da imagem original, MEV-ER.

Como pode ser observado, os pontos 1 e 2 indicam as fases encontradas. Na tabela 3 está apresentada a composição química desses pontos.

Tabela 3: Composição química dos pontos analisados via MEV/EDS (\% em massa).

\begin{tabular}{ccccc}
\hline PONTO & $\mathbf{M g O}(\%)$ & $\mathbf{A l}_{2} \mathbf{O}_{3}(\%)$ & $\mathbf{S i O}_{2}(\%)$ & $\mathbf{C a O}(\%)$ \\
\hline 1 & 0,6 & 6,1 & 34,5 & 58,9 \\
\hline 2 & 1,4 & 25,4 & 30,0 & 43,3 \\
\hline
\end{tabular}

A partir da análise da figura 2 e da tabela 3, percebe-se que a amostra apresenta uma matriz mais homogênea, representada pelo ponto 2 , sendo a fase líquida da amostra, e uma fase sólida, representada pelo ponto 1. Através da composição química, pode-se afirmar que a fase sólida da amostra seja de $2 \mathrm{CaO} \cdot \mathrm{SiO}_{2}$.

As tabelas 4 e 5 apresentam os resultados da composição química esperada para essa amostra através da simulação termodinâmica.

Tabela 4: Porcentagens calculadas para as fases sólida e líquida a $1600^{\circ} \mathrm{C}$.

\begin{tabular}{cc}
\hline Fase & \% em massa \\
\hline Líquida & 96,02 \\
\hline Sólida & 3,98 \\
\hline
\end{tabular}

Tabela 5: Composição química calculada para as fases líquida e sólida a 1600C (\% em massa).

\begin{tabular}{cc}
\hline Componente & \% na Fração Líquida \\
\hline $\mathrm{Al}_{2} \mathrm{O}_{3}$ & 20,82 \\
\hline $\mathrm{SiO}_{2}$ & 24,58 \\
\hline $\mathrm{MgO}$ & 5,15 \\
\hline $\mathrm{CaO}$ & 49,45 \\
\hline
\end{tabular}

\begin{tabular}{cc}
\hline Componente & \% na Fração Sólida \\
\hline $2 \mathrm{MgO} . \mathrm{SiO}_{2}$ & 2,66 \\
\hline $2 \mathrm{CaO} . \mathrm{SiO}_{2}$ & 97,34
\end{tabular}


Comparando os resultados da análise de MEV/EDS com os resultados da simulação, percebe-se há boa compatibilidade entre eles, tendo em vista que a análise de MEV/EDS é semi quantitativa. Conforme se observa nas tabelas 4 e 5 e na figura 2, a fase líquida é proeminente, e a fase sólida corresponde ao composto $2 \mathrm{CaO} . \mathrm{SiO}_{2}$.

\section{Amostra 2}

A figura 3 representa a micrografia da amostra de escória que contém $7 \%$ de $\mathrm{MgO}$.

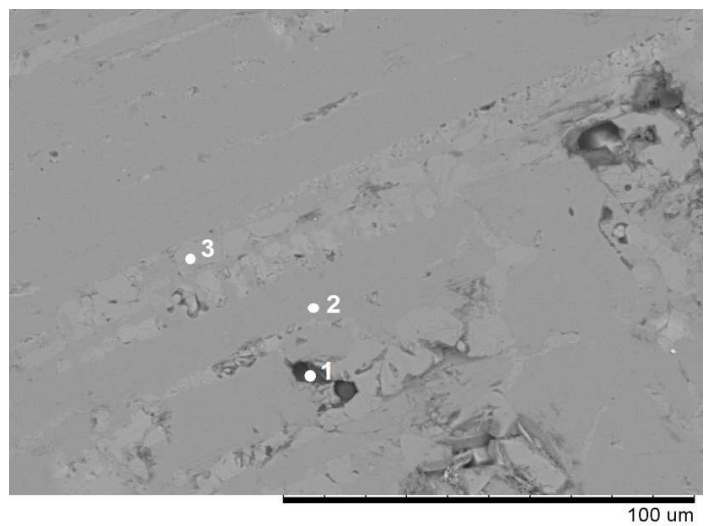

Figura 3: Pontos 1, 2 e 3 analisados na amostra de 7\% de MgO. Aumento de 2000x da imagem original, MEV-ER.

Na figura 3, os pontos 2 e 3 representam as fases presentes nessa amostra. Já o ponto 1 é uma irregularidade na amostra. Isso pode ser comprovado através da tabela 6, que apresenta a composição química dos três pontos. Os pontos 1 e 2 corresponde a mesma fase.

Tabela 6: Composição química dos pontos analisados via MEV/EDS (\% em massa).

\begin{tabular}{ccccc}
\hline PONTO & $\mathbf{M g O}(\%)$ & $\mathbf{A l}_{\mathbf{2}} \mathbf{O}_{\mathbf{3}}(\%)$ & $\mathbf{S i O}_{\mathbf{2}}(\%)$ & $\mathbf{C a O}(\%)$ \\
\hline 1 & 1,8 & 26,5 & 27,8 & 44,0 \\
\hline 2 & 2,0 & 26,7 & 28,7 & 42,7 \\
\hline 3 & 4,6 & 6,6 & 34,3 & 54,5
\end{tabular}

A tabela 7 apresenta o resultado da composição química da fase líquida para essa amostra, através da simulação termodinâmica. Não foi formada fase sólida nesse caso.

Tabela 7: Composição química calculada da fase líquida a 1600두 (\% em massa).

\begin{tabular}{cc}
\hline Componente & \% na Fração Líquida \\
\hline $\mathrm{Al}_{2} \mathrm{O}_{3}$ & 20,00 \\
\hline $\mathrm{SiO}_{2}$ & 24,33 \\
\hline $\mathrm{MgO}$ & 7,00 \\
\hline $\mathrm{CaO}$ & 48,67
\end{tabular}

Os resultados obtidos via simulação termodinâmica mostram a formação apenas de uma fase, a fase líquida. Entretanto, o que se observou pela análise de MEV/EDS foi também a formação de uma fase sólida, ponto 3. O que deve ser levado em conta é que os resultados da simulação são para a temperatura de $1600^{\circ} \mathrm{C}$, mas as amostras tiveram um resfriamento lento, e por isso, podem surgir novas fases. Essa 
fase sólida parece ser $2 \mathrm{CaO} . \mathrm{SiO}_{2}$, provavelmente formado durante o resfriamento da amostra.

Escória totalmente líquida beneficia os processos de dessulfuração e outras reações do refino secundário do aço. Fase sólida significativa na escória pode aumentar a viscosidade e retardar algumas operações do refino [6].

\section{Amostra 3}

A figura 4 representa a micrografia da amostra de escória que contém 15\% de MgO.

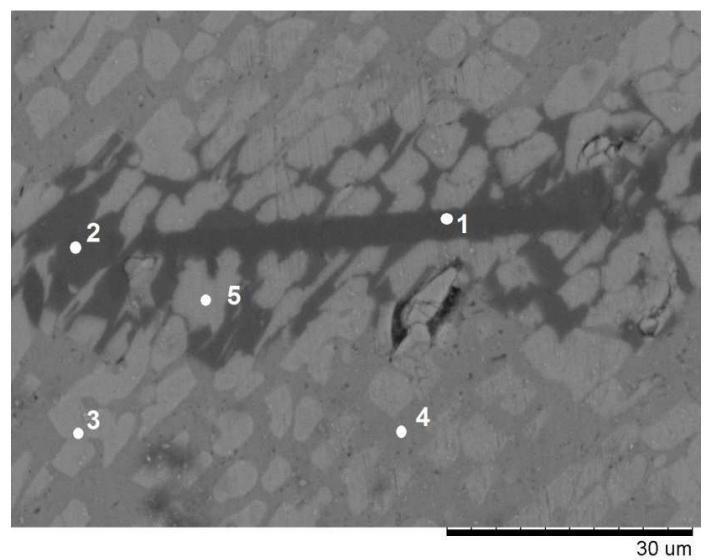

Figura 4: Pontos 1 a 5 analisados na amostra de 15\% de MgO. Aumento de 2000x da imagem original, MEV-ER.

O que se observa na figura 4 é a presença de três fases distintas. Sendo uma fase líquida (matriz homogênea), uma fase sólida de $2 \mathrm{CaO}^{-} \mathrm{SiO}_{2}$ (regiões cinza claro), e uma fase sólida de $\mathrm{MgO}$ (região cinza escuro). A tabela 8 apresenta a composição química dos pontos analisados.

Tabela 8: Composição química dos pontos analisados via MEV/EDS (\% em massa).

\begin{tabular}{ccccc}
\hline PONTO & $\mathbf{M g O}(\%)$ & $\mathbf{A l}_{2} \mathbf{O}_{3}(\%)$ & $\mathbf{S i O}_{2}(\%)$ & $\mathbf{C a O}(\%)$ \\
\hline 1 & 62,2 & 12,4 & 11,2 & 14,3 \\
\hline 2 & 21,6 & 52,4 & 11,3 & 14,6 \\
\hline 3 & 7,5 & 7,0 & 33,8 & 51,7 \\
\hline 4 & 5,7 & 32,9 & 20,6 & 40,9 \\
\hline 5 & 9,9 & 7,2 & 32,5 & 50,4 \\
\hline
\end{tabular}

Pode-se notar pela tabela 8 que os pontos 1 e 2 são fase sólida de $\mathrm{MgO}$. Os pontos 3 e 5 representam a fase sólida de $2 \mathrm{CaO} . \mathrm{SiO}_{2}$, e o ponto 4 representa a fase líquida. As tabelas 9 e 10 apresentam os resultados da composição química esperada para essa amostra através da simulação termodinâmica.

Tabela 9: Porcentagens calculadas para as fases sólida e líquidas.

\begin{tabular}{cc}
\hline Fase & \% em massa \\
\hline Líquida & 95,05 \\
\hline Sólida & 4,95 \\
\hline
\end{tabular}


Tabela 10: Composição química calculada para as fases líquida e sólida (\% em massa).

\begin{tabular}{cc}
\hline Componente & \% na Fração Líquida \\
\hline $\mathrm{Al}_{2} \mathrm{O}_{3}$ & 21,03 \\
\hline $\mathrm{SiO}_{2}$ & 22,80 \\
\hline $\mathrm{MgO}$ & 45,58 \\
\hline $\mathrm{CaO}$ & 10,59 \\
\hline
\end{tabular}

\begin{tabular}{cc}
\hline Componente & \% na Fração Sólida \\
\hline $\mathrm{CaO}$ & 0,17 \\
\hline $\mathrm{MgO}$ & 99,53 \\
\hline $\mathrm{Al}_{2} \mathrm{O}_{3}$ & 0,30 \\
\hline
\end{tabular}

Através dos resultados da simulação termodinâmica, se pode notar que existe apenas a formação de uma fase sólida, de MgO. Entretanto, novamente, ocorreu a formação de duas fases sólidas, uma de $\mathrm{MgO}$ e outra de $2 \mathrm{CaO} \cdot \mathrm{SiO}_{2}$, causando divergência entre os dois resultados. A fase sólida de $2 \mathrm{CaO} . \mathrm{SiO}_{2}$ foi formada, provavelmente, no resfriamento da amostra, já que esse foi bastante lento, o que pode provocar a formação de novas fases não esperadas nas amostras.

\section{Amostra 4}

A figura 5 representa a micrografia da amostra de escória que contém 20\% de MgO.

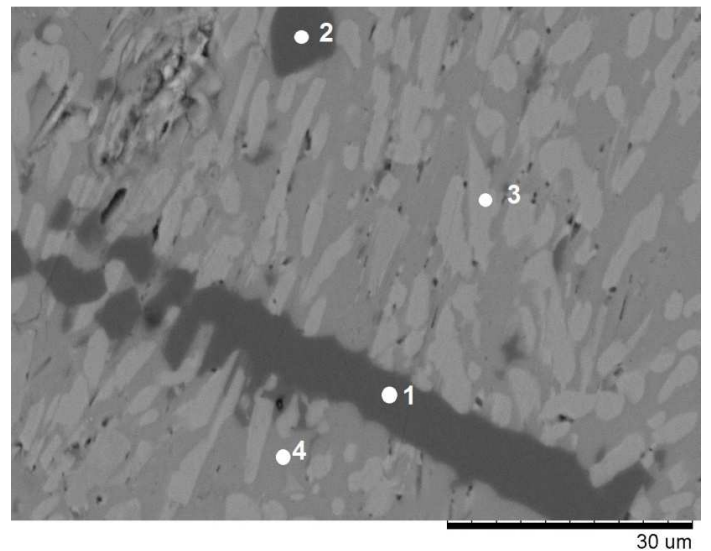

Figura 5: Pontos 1 a 4 analisados na amostra de 20\% de MgO. Aumento de 2000x da imagem original, MEV-ER.

Claramente percebe-se na figura 5 a presença de duas fases sólidas, uma de cor cinza escuro e outra de cor cinza claro, além da matriz, que é a região mais homogênea. A tabela 11 apresenta a composição química dos pontos analisados.

Tabela 11: Composição química dos pontos analisados via MEV/EDS (\% em massa).

\begin{tabular}{ccccc}
\hline PONTO & $\mathbf{M g O}(\%)$ & $\mathbf{A l}_{2} \mathbf{O}_{\mathbf{3}}(\%)$ & $\mathbf{S i O}_{2}(\%)$ & $\mathbf{C a O}(\%)$ \\
\hline 1 & 62,7 & 10,8 & 9,9 & 16,6 \\
\hline 2 & 62,3 & 10,4 & 10,0 & 17,2 \\
\hline 3 & 6,1 & 15,6 & 25,2 & 53,1 \\
\hline 4 & 5,3 & 25,8 & 21,2 & 47,7 \\
\hline
\end{tabular}

Através da composição química fornecida pela análise de MEV/EDS, pode-se notar que o os pontos 1 e 2 são a fase sólida de $\mathrm{MgO}$ e o ponto 3 é fase sólida de $2 \mathrm{CaO} \cdot \mathrm{SiO}_{2}$. Já o ponto 4 é a fase líquida.

As tabelas 12 e 13 apresentam os resultados da composição química esperada para essa amostra através da simulação termodinâmica. 
Tabela 12: Porcentagens calculadas para as fases sólida e líquidas.

\begin{tabular}{cc}
\hline Fase & \% em massa \\
\hline Líquida & 89,73 \\
\hline Sólida & 10,27 \\
\hline
\end{tabular}

Tabela 13: Composição química calculada para as fases líquida e sólida (\% em massa).

\begin{tabular}{cc}
\hline Componente & $\begin{array}{c}\text { \% na Fração } \\
\text { Líquida }\end{array}$ \\
\hline $\mathrm{Al}_{2} \mathrm{O}_{3}$ & 22,25 \\
\hline $\mathrm{SiO}_{2}$ & 22,29 \\
\hline $\mathrm{MgO}$ & 10,90 \\
\hline $\mathrm{CaO}$ & 44,56 \\
\hline
\end{tabular}

\begin{tabular}{cc}
\hline Componente & \% na Fração Sólida \\
\hline $\mathrm{CaO}$ & 0,16 \\
\hline $\mathrm{MgO}$ & 99,52 \\
\hline $\mathrm{Al}_{2} \mathrm{O}_{3}$ & 0,32 \\
\hline
\end{tabular}

Pela simulação termodinâmica, percebe-se que é esperado apenas a formação de uma fase sólida, de $\mathrm{MgO}$. Contudo, verificou-se a formação de fase sólida de $2 \mathrm{CaO} . \mathrm{SiO}_{2}$, provavelmente formado durante o resfriamento da amostra, como ocorreu nas amostras 2 e 3.

Os resultados encontrados condizem com o trabalho de Gran et al [5], apesar da diferente metodologia utilizada nos trabalhos.

\subsubsection{Difração de Raios X}

Para se conhecer os compostos presentes nas amostras foi realizada a análise de difração de raios X. A figura 6 apresenta os gráficos obtidos para cada amostra com a caracterização de cada pico.

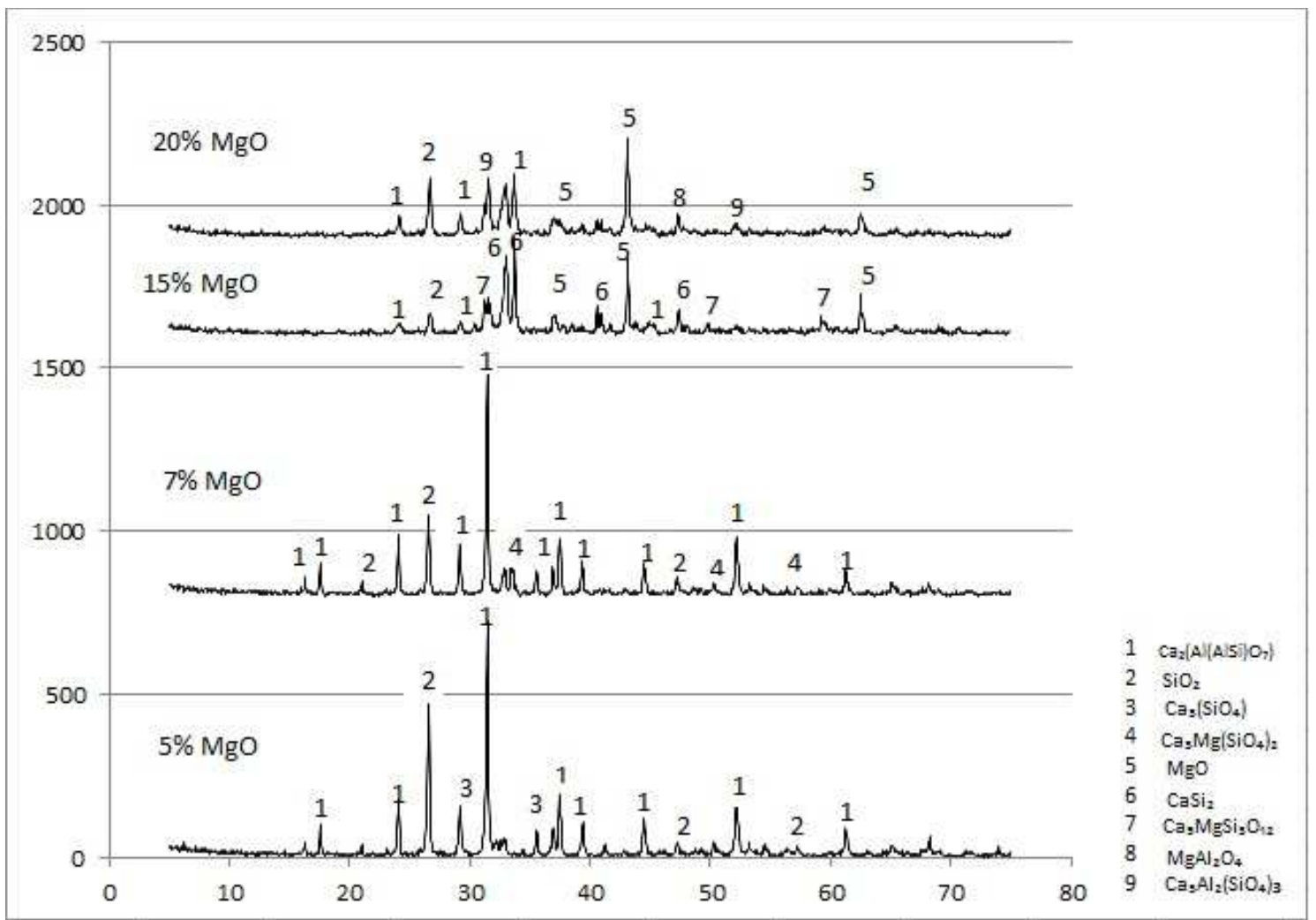

Figura 6: Resultados obtidos na difração de raios X. 
O que se observa primeiramente na figura 6 é a grande semelhança nos resultados das amostras de 5 e $7 \%$ de $\mathrm{MgO}$ e das amostras de 15 e 20\% de MgO. Isso se dá pela semelhança maior na composição química dessas amostras.

Nas amostras de 5 e $7 \%$ de $\mathrm{MgO}$ foram comprovadas a presença de duas fases principais, que são gehlenite $\left(\mathrm{Ca}_{2}\left(\mathrm{Al}(\mathrm{AISi}) \mathrm{O}_{7}\right)\right)$ e Quartzo $\left(\mathrm{SiO}_{2}\right)$, além desses compostos, aparece também o tricalcio silicato $\left(\mathrm{Ca}_{3}\left(\mathrm{SiO}_{4}\right)\right)$.

Já na amostra contendo $15 \%$ de $\mathrm{MgO}$, foi constatada a presença de cálcio silicato $\left(\mathrm{CaSi}_{2}\right)$ e periclase $(\mathrm{MgO})$. Ademais, verificou-se também gehlenite e quartzo com picos menores.

Por último, na amostra de $20 \%$ de $\mathrm{MgO}$, a análise comprovou a presença de periclase, sendo esse o composto predominante. Além disso, a amostra apresentou gehlenite, quartzo e cálcio alumínio silicato $\left(\mathrm{Ca}_{3} \mathrm{Al}_{2}\left(\mathrm{SiO}_{4}\right)_{3}\right)$.

Os resultados são condizentes com os obtidos nas outras análises. Pode-se notar que a maioria dos compostos acusados na difratometria refere-se à fase líquida das amostras a $1600^{\circ} \mathrm{C}$, já que esta fase é predominante e pode ocultar os compostos da fase sólida [10].

Isso é de extrema importância, já que o MgO atua para tornar a escória compatível com os refratários utilizados no processo de fabricação do aço, e essa saturação evita o desgaste do refratário do forno-panela. Além disso, atingir o nível de saturação do $\mathrm{MgO}$ na escória é fundamental, já que menores teores de $\mathrm{MgO}$ na fase líquida implica em menor quantidade de $\mathrm{Mg}$ no aço, reduzindo a formação de inclusões de espinélio.

Como consideração final, destaque-se que o controle da composição química da escória deve ser muito rigoroso, já que pequenas mudanças na composição podem alterar as fases presentes e aumentar a fração sólida, aumentando assim a viscosidade e tornando algumas reações do refino secundário do aço menos eficientes.

\section{CONCLUSÕES}

Após a análise dos resultados, podem-se chegar as seguintes conclusões a respeito da caracterização das fases das amostras de escória do sistema CMAS:

- Os experimentos feitos em laboratório mostraram-se eficazes para a análise e determinação das fases presentes nas amostras de escória e para o estudo das escórias de forno-panela.

- A amostra 1, com 5\% de MgO, teve comportamento semelhante ao esperado. Já as demais amostras apresentaram comportamento divergente à simulação termodinâmica. Entretanto, os resultados obtidos experimentalmente estão de acordo com a bibliografia.

- Para os teores de reagentes utilizados, notou-se que há uma saturação de MgO na escória a $1600^{\circ} \mathrm{C}$ para as amostras de 15 e $20 \%$ de MgO.

- Verificou-se a formação de fases não esperadas nas amostras 2, 3 e 4. Como o resfriamento lento das amostras pode causar a formação de novas fases na escória, em trabalhos futuros serão realizados experimentos com resfriamento rápido para análise das fases formadas.

\section{Agradecimentos}

A autora agradece ao professor Antônio C. F. Vilela, Coordenador do Laboratório de Siderurgia, pela oportunidade de experiência junto ao laboratório. Ao CNPq e 
Fundação Luiz Englert pelo suporte financeiro. Ao Professor Dr. Wagner Viana Bielefeldt pelo apoio, orientação e amizade. Ao Dr. Eng. Julio Aníbal Morales Pereira pela amizade, ajuda e conselhos. E a equipe do Laboratório de Siderurgia pelo cooperativismo e prestatividade.

\section{REFERÊNCIAS}

1 BARTOSIAKI, B.G. Characterization and Study of the formation, treatment and removal of non-metallic inclusions in SAE 52100 Steel. 19th IAS Steel Conference, Rosário, 2013.

2 Manual de Aciaria - Diagramas Ternários. Gerdau, 2013.

3 REIS B.H.; ET AL.; Investigation of the ability of secondary refining slags to absorb inclusions during steel production. 19th IAS Steel Conference, Rosário, 2013.

4 DAHL, F.; BRANDBERG, J.; SICHEN, D.: Characterization of Melting of Some Slags in the $\mathrm{Al}_{2} \mathrm{O}_{3}-\mathrm{CaO}-\mathrm{MgO}-\mathrm{SiO}_{2}$ Quaternary System. ISIJ International, Vol. 46 (2006), No. 4, pp. 614-616.

5 GRAN, J.; WANG Y.; SICHEN, D.: Experimental determination of the liquidus in the high basicity region in the $\mathrm{Al}_{2} \mathrm{O}_{3}(30$ mass $\%)-\mathrm{CaO}-\mathrm{MgO}-\mathrm{SiO}_{2}$ system. Computer Coupling of Phase Diagrams and Thermochemistry 35 (2011), pp. 249-254.

6 BIELEFELDT W.V., Estudo do Tratamento de Inclusões com Cálcio na Fabricação do Aço SAE 8620. Porto Alegre, 2005. Dissertação de Mestrado, Escola de Engenharia, Departamento de Metalurgia, UFRGS.

7 C. W. BALE, P. CHARTRAND, S. A. DEGTEROV et al: FactSage Thermochemical Software and Databases. Calphad, 2002, v. 26, pp. 189-228.

8 C. W. BALE, E. BÉLISLE, P. CHARTRAND et al: FactSage thermochemical software and databases - recent developments. Calphad, 2009, v. 33, pp. 295-311.

9 Manual de Aciaria - Fundamentos de Escórias. Gerdau, 2013.

10 ZANON, E. B. Determinação Experimental e Simulação Termodinâmica das Fases Presentes em Escórias de Refino Secundário de Aços. Trabalho de Diplomação, Escola de Engenharia, UFRGS, 2013. 